\title{
Evaluating the effects of consolidation on intrusion and retraction using temporary anchorage devices - a FEM study
}

\author{
Monica Namburi*, Sleevaraju Nagothu, Chetan S. Kumar, N. Chakrapani, C. H. Hanumantharao
}

and Supradeep K. Kumar

\begin{abstract}
Background: Extraction of premolars and retracting the anterior teeth using mini-implants and anterior retraction hooks became advent now a day. In such treatments, consolidation of arches is not done in regular practice. So, the present study is concentrated on effects of consolidation in two implant and three implant combinations of retraction and intrusion.
\end{abstract}

Methods: A three-dimensional FEM model of maxillary teeth and periodontal ligament housed in the alveolar bone with the first premolars extracted is generated with appropriate number of elements and nodes. The models were broadly divided into two groups according to the no. of implants. Mini-implants were placed bilaterally between the second premolar and molar at varying heights $(7,10,13 \mathrm{~mm})$ in group I, and along with bilateral implants, an additional mid-implant is placed between the central incisors as group II. Brackets with 0.022 slot were placed on the teeth, $19 \times 25$ SS wire is placed in the brackets, an anterior retraction hook was placed at $9 \mathrm{~mm}$ height, and analysis was done to evaluate the stresses and displacement patterns in consolidation and non-consolidation models.

Results: The results showed that consolidation of the anterior teeth during intrusion and retraction shows various advantages such as less stresses on the bone, PDL, implant, teeth, and no labial flaring of the anterior teeth and three implant system, i.e., two bilateral implant at $10 \mathrm{~mm}$ and a mid-implant at $12 \mathrm{~mm}$ between the centrals has shown to be better than other models as bodily movement is observed.

Conclusion: Consolidation is better than non consolidation during enmasse retraction and intrusion.

Keywords: FEM, Mini-screws, Consolidation, Bilateral implants, Three implants, Intrusion, Retraction, PDL, Stress distribution, Initial displacements

\section{Background}

Dental protrusion is common in many ethnic groups around the world. It is characterized by dento-alveolar flaring of only maxillary teeth or both the maxillary and the mandibular anterior teeth with resultant protrusion of the lips and the convexity of the face [1]. Extracting the first four premolars and retracting the anterior segments with maximum anchorage is one of the ways to reduce the protrusion and to straighten the patient's profile. The retraction of four incisors after canine retraction is accepted as a method to minimize the mesial movement of

\footnotetext{
* Correspondence: m.ortho16888@gmail.com

St. Joseph Dental College, Eluru, Andhra Pradesh, India
}

the posterior teeth segment, whereas en-masse retraction of six anterior teeth may create anchorage problems. Anchorage may be aided by the use of intra- and extraoral appliances. However, intraoral anchorage devices may provide insufficient anchorage, whereas extra-oral appliances provide a sufficient anchorage but are dependent on patient compliance [2]. The goal of orthodontic treatment is to achieve the desired tooth movement with minimum unwanted side effects and to improve patient aesthetics [3].

In retraction mechanics, temporary anchorage devices (TADs) or orthodontic mini-implants (OMIs) are used for anchorage purposes $[4,5]$, which gained popularity and are used successfully in orthodontic treatment. Hooks are 
Table 1 Material properties

\begin{tabular}{lll}
\hline Material & $\begin{array}{l}\text { Modulus of elasticity } \\
(\mathrm{MPa})\end{array}$ & Poisson's ratio \\
\hline Tooth & 80,000 & 0.3 \\
PDL & 0.1 & 0.45 \\
Stainless steel wire and brackets & $210 \times 10^{3}$ & 0.3 \\
Cortical/hard bone & 13,800 & 0.26 \\
Trabecular/soft bone & 345 & 0.31 \\
Titanium implants & $110 \times 10^{3}$ & 0.3
\end{tabular}

used on the archwire as force application points to achieve anterior retraction. These hooks or power arms can be crimped, screwed on, soldered to the archwire with silver solder, or welded [6]. The force is applied directly from the implant to the power arms with the help of e-chains or coil springs for effective space closure. This force vector can be controlled by changing mini-implant insertion height and/or anterior retraction hook height, thereby raising a number of different force action line alternatives. Orthodontists therefore, prior to mini-implant installation, should define which force action lines will be employed and determine the force vector which will exert upon the anterior teeth. In en-masse retraction consolidation of the arches which means making them as a single unit using ligature wire as the anterior (canine to canine) and posterior segments (premolar to molars on one side as one segment and on the other side as another segment) should be done. Consolidation of arches is advised to inhibit the unwanted tooth movement.

Application of engineering knowledge in dentistry with the use of computational techniques has helped to understand oral biomechanics aspects. One of such software is finite element analysis (FEM) [7]. This method can simplify the physiologic responses of dento-alveolar complex to orthodontic forces by exhibiting quantitative data, and is recently preferred by the researchers of the field [8]. The main advantage of using finite element analysis is that many alternative designs can be tried out for their validity, safety, and integrity using the computer, even before the first prototype is built [9]. In spite

Table 2 Nodes and elements

\begin{tabular}{llll}
\hline S.No. & Description & Number of elements & Number of nodes \\
\hline 1 & Hard bone & 79,455 & 25,150 \\
2 & Soft bone & 94,844 & 24,957 \\
3 & Mini-implants & 14,259 & 4470 \\
4 & Brackets & 52,730 & 16,856 \\
5 & Wire & 100 & 101 \\
6 & Teeth & 20 & 22 \\
7 & PDL & 46,570 & 13,640 \\
8 & Anterior retraction hook & 20 & 22 \\
\hline
\end{tabular}

Total nodes in the study $=43,887$. Total elements in the study $=209,807$

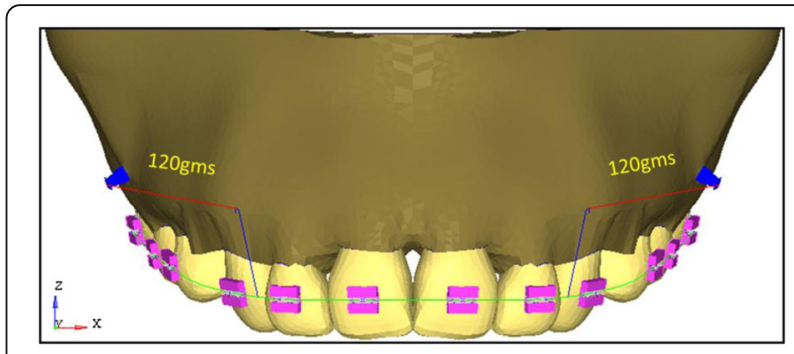

Fig. 1 Bilateral implant model

of the significant advances that have been made in developing finite element models, the results obtained must be carefully examined before they can be used.

Many studies evaluated the stress in the bone [10, 11], PDL [12-18], implants [19-22] in mini-implant-assisted retraction [23] with different height of implants and retraction hooks [24, 25] and materials [26, 27]. But there are no studies which evaluated the stresses on the bone and PDL in two implant and three implant combinations. There are no studies regarding the effects of consolidation during retraction. So, the present study was conducted to evaluate the analysis of stresses and displacement pattern in two implant and three implant combinations with and without consolidation.

\section{Methods}

In this study, 12 finite element models were created with 43,887 nodes and 209,807 elements (Tables 1 and 2) with variations in number of mini-implants, height of placement of bilateral mini-implants, and different force levels from the mid-implant and with and without consolidation. The FEM model used in the present study is having the first premolars extracted, and the implants were placed between the roots of the second premolars and first molars $[6,28]$ to retract the anterior teeth. The present study includes the implant of width $1.3 \mathrm{~mm} \times 8 \mathrm{~mm}$ [28-30]. Bilateral implants will be angulated to $30^{\circ}$ to the long axis of the occlusal plane. The anterior retraction hook is placed between the canine and lateral brackets [31] at a 9-mm height [30, 32], (Fig. 1). The PDL space is maintained equal at $0.25 \mathrm{~mm}$ in all teeth and isotropic linear properties are given for PDL $[1,33,34]$.

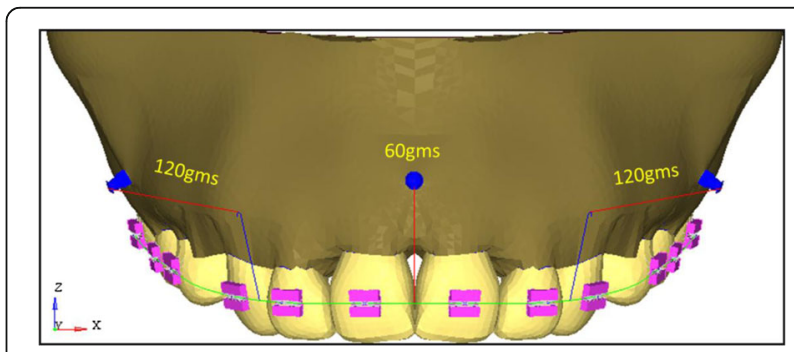

Fig. 2 Three implant model 


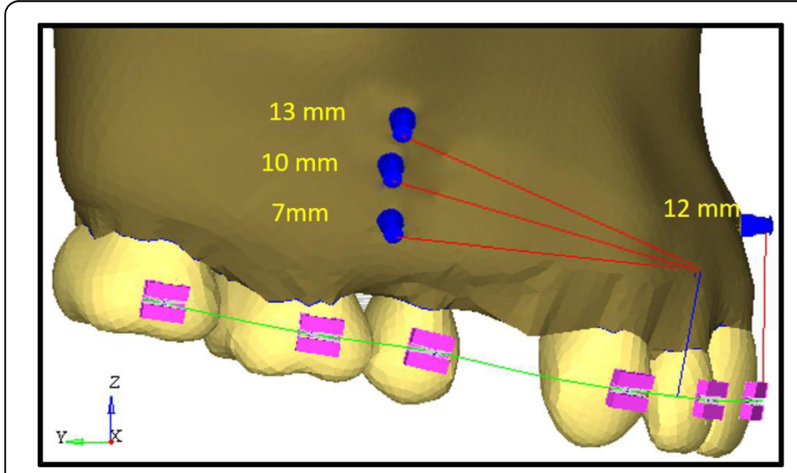

Fig. 3 Implant heights

The mid-implant is placed perpendicular to the occlusal plane. The anterior retraction hook is placed constant at $9 \mathrm{~mm}$ from the archwire oriented gingivally and a force of $120 \mathrm{~g}$ was given from bilateral implants for retraction and a force of $60 \mathrm{~g}$ is given from mid-implant for intrusion purpose (Fig. 2). The stress distribution patterns in teeth, PDL, and bone along with anterioposterior and vertical displacements are observed in consolidation, non-consolidation in two implant and three implant systems at low pull $(7 \mathrm{~mm})$, medium pull $(10 \mathrm{~mm})$, and high pull $(13 \mathrm{~mm})$ bilateral implant heights from the arch wire and in three implant models the mid-implant is placed constant at $12-\mathrm{mm}$ height from the archwire (Fig. 3). The models were broadly divided into two groups.

Group I: Bilateral implants placed at different heights $(7,10$, and $13 \mathrm{~mm})$ in between the second premolar and first molar.

Group II: Along with bilateral implants (7, 10, and $13 \mathrm{~mm}$ ), an additional mid-implant is placed in between the two central incisors at 12-mm height from the arch wire.

The analysis was carried out using ANSYS 12.1 version software in Bangalore, INDIA. The initial displacement patterns in anterio-posterior direction (Fig. 4, Table 3), vertical direction (Fig. 5, Table 4), and stress patterns in the PDL (Fig. 6, Table 5), bone (Fig. 7, Table 6), teeth (Fig. 8, Table 7), and implant in two implant and three

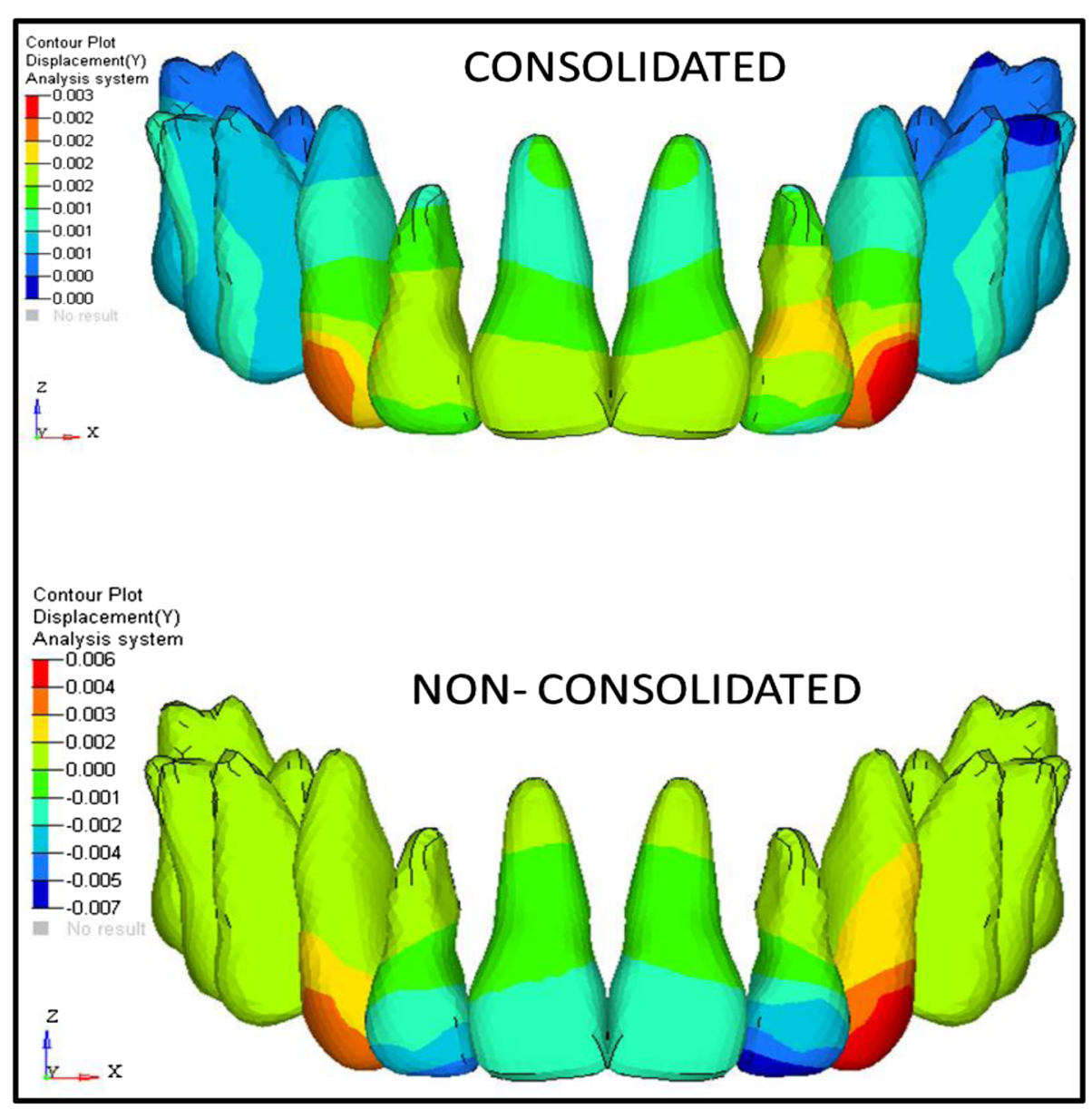

Fig. 4 Anterio-posterior displacement pattern 
Table 3 Anterio-posterior displacements in consolidated and non-consolidated model in group I and group II models (mm)

\begin{tabular}{|c|c|c|c|c|c|c|c|c|c|c|c|c|c|}
\hline & \multirow{3}{*}{$\begin{array}{l}\text { Implant } \\
\text { heights (mm) }\end{array}$} & \multicolumn{4}{|c|}{ Central incisor } & \multicolumn{4}{|c|}{ Lateral incisor } & \multicolumn{4}{|l|}{ Canine } \\
\hline & & \multicolumn{2}{|c|}{ Consolidated } & \multicolumn{2}{|c|}{ Non-consolidated } & \multicolumn{2}{|c|}{ Consolidated } & \multicolumn{2}{|c|}{ Non-consolidated } & \multicolumn{2}{|c|}{ Consolidated } & \multicolumn{2}{|c|}{ Non-consolidated } \\
\hline & & Crown & Apex & Crown & Apex & Crown & Apex & Crown & Apex & Crown & Apex & Crown & Apex \\
\hline \multirow[t]{3}{*}{ Group I } & 7 & 0.027 & 0.012 & 0.013 & 0.01 & 0.023 & 0.017 & -0.022 & 0.021 & 0.033 & 0.011 & 0.054 & 0.011 \\
\hline & 10 & 0.024 & 0.011 & 0.01 & 0.009 & 0.022 & 0.015 & -0.029 & 0.018 & 0.03 & 0.009 & 0.049 & 0.01 \\
\hline & 13 & 0.021 & 0.009 & 0.005 & 0.008 & 0.017 & 0.013 & -0.034 & 0.015 & 0.026 & 0.008 & 0.045 & 0.008 \\
\hline \multirow[t]{3}{*}{ Group II } & 7 & 0.01 & 0.0125 & -0.011 & 0.011 & 0.009 & 0.01 & -0.013 & 0.01 & 0.013 & 0.009 & 0.021 & 0.009 \\
\hline & 10 & 0.002 & 0.001 & -0.002 & 0.001 & 0.001 & 0.001 & -0.003 & 0.002 & 0.002 & 0.001 & 0.006 & 0.001 \\
\hline & 13 & 0.012 & 0.011 & -0.022 & 0.009 & 0.008 & 0.009 & -0.049 & 0.009 & 0.017 & 0.006 & 0.034 & 0.006 \\
\hline
\end{tabular}

Inference (positive(+) : palatal movement; negative(-): labial movement)

Group I: In consolidation, palatal tipping is seen, and in non-consolidation, labial flaring is seen in lateral incisor

Group II: In consolidation, 10-mm implant height model showed bodily movement, 7- and 13-mm implant height showed palatal tipping and in non-consolidation, labial flaring of the teeth observed in centrals and laterals

implant scenarios at different implant heights were analyzed (Table 8).

\section{Discussion}

The goal of the present study is to compare and evaluate the effects of consolidation on intrusion and retraction in two implant and three implant scenarios.

In this study, 12 finite element models were created with variations in number of mini-implants, height of placement of bilateral mini-implants and different force levels from the mid-implant and with and without consolidation.

The bilateral implants will be angulated to $30^{\circ}$ to the long axis of the occlusal plane as per the studies conducted by Kyung HM, Park HS et al. [2], Ju-Eun Lim [35], and Fathima Jasmine [36] where they stated that if the mini-implant is angulated, the cortical bone and implant interface area will be increased as the most of the

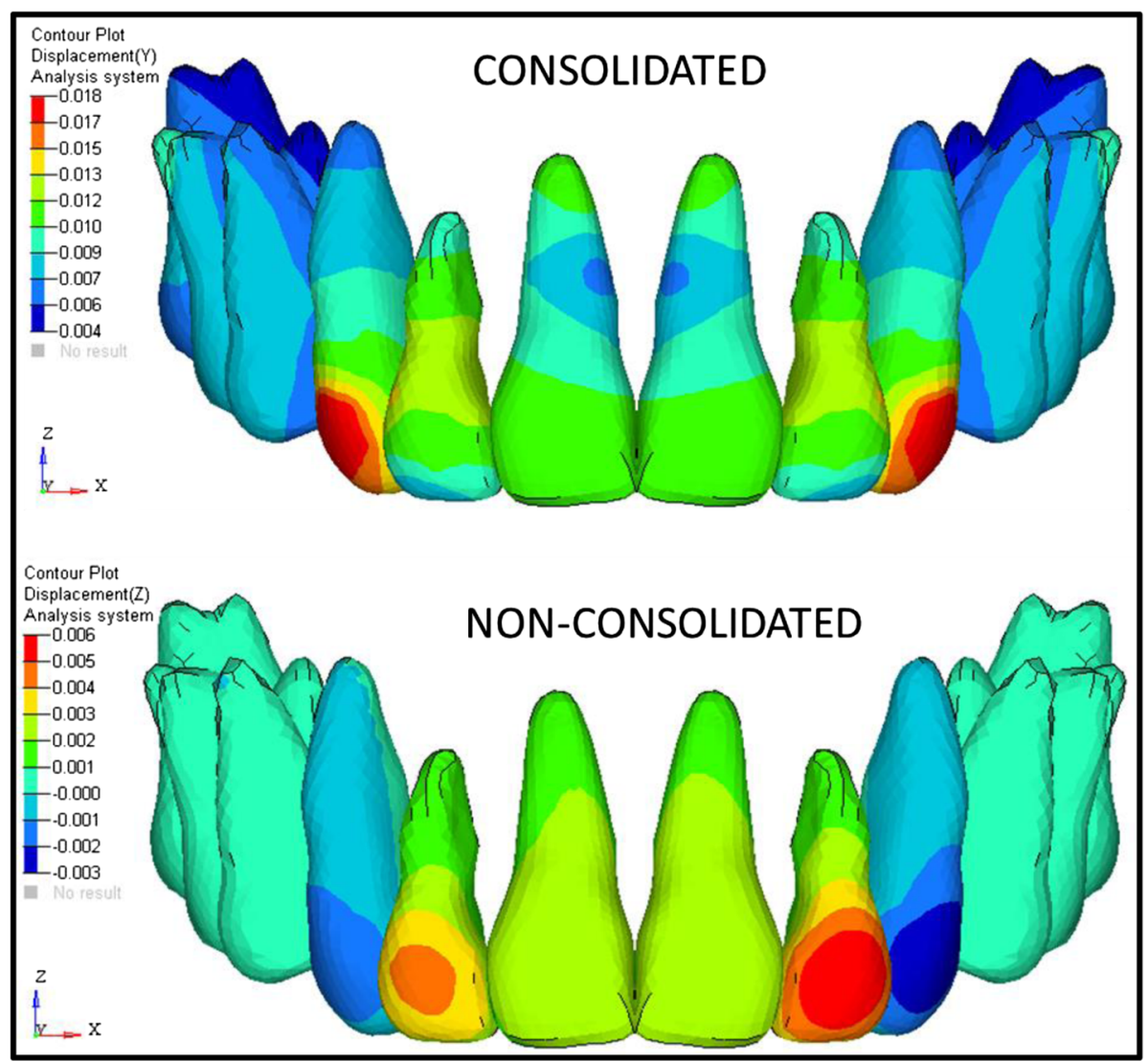

Fig. 5 Vertical displacement patterns 
Table 4 Vertical displacements in group I and group || consolidated and non-consolidated models (mm)

\begin{tabular}{|c|c|c|c|c|c|c|c|}
\hline & \multicolumn{3}{|c|}{ Consolidated } & \multicolumn{3}{|c|}{ Non-consolidated } \\
\hline & & Central & Lateral & Canine & Central & Lateral & Canine \\
\hline \multirow[t]{3}{*}{ Group I } & $7 \mathrm{~mm}$ & -0.006 & 0.007 & -0.016 & -0.002 & 0.0027 & -0.026 \\
\hline & $10 \mathrm{~mm}$ & -0.004 & -0.004 & -0.01 & 0 & -0.02 & -0.026 \\
\hline & $13 \mathrm{~mm}$ & -0.003 & 0.012 & -0.014 & 0.005 & 0.035 & -0.023 \\
\hline \multirow[t]{3}{*}{ Group II } & $7 \mathrm{~mm}$ & 0.006 & 0.007 & -0.003 & 0.016 & 0.016 & -0.009 \\
\hline & $10 \mathrm{~mm}$ & 0.001 & 0.002 & -0.002 & 0.002 & 0.006 & -0.003 \\
\hline & $13 \mathrm{~mm}$ & 0.008 & 0.019 & -0.008 & 0.023 & 0.044 & -0.02 \\
\hline
\end{tabular}

Inference: (positive (+) : intrusion; negetive(-): extrusion)

Group I: In consolidation, extrusion of canines and centrals observed in all cases, laterals extruded in 10- $\mathrm{mm}$ implant height and in other models intrusion of

laterals observed. In non-consolidation, extrusion of canines observed in all cases whereas laterals showed extrusion in 10- $\mathrm{mm}$ implant height and centrals showed extrusion in 7-mm implant height, intrusion of centrals and laterals observed in 13-mm implant height model

Group II: In consolidation and non-consolidation, extrusion of canines observed and centrals and laterals intruded in all models

implant will be in the cortical bone, and thus, the stability will be increased and also the proper angle of insertion is important for cortical anchorage, patient's safety, and biomechanical control and mid-implant is placed perpendicular to the occlusal plane. According to Madhupura et al. [28] and Masahiro Iijima [30], the implant of $8 \mathrm{~mm} \times 1.3 \mathrm{~mm}$ is placed because longer miniscrew implants were associated with a greater incidence of sinus and bi-cortical perforations. According to Tina Chugh et al. [37], the highest cortical bone density was observed between the second premolar and first molar. So, the implant was placed at the second premolar and first molar regions. In Gjessing's [30] rule of thumb, the position of the center of resistance of the anterior segment will be at 9-10 $\mathrm{mm}$ apically, so the anterior retraction hook is placed constant at $9 \mathrm{~mm}$ from the archwire oriented gingivally and a force of $120 \mathrm{~g}$ was given from bilateral implants for retraction and a force of $60 \mathrm{~g}$ is given from mid-implant for intrusion (Figs. 1 and 2). The stress distribution patterns in teeth, PDL, and bone along with anterio-posterior and vertical displacements are observed in consolidation, non-consolidation in two implant and three implant systems at low pull $(7 \mathrm{~mm})$, medium pull $(10 \mathrm{~mm})$, and high pull $(13 \mathrm{~mm})$ bilateral (Fig. 3) implant heights from the archwire, and in three implant models, the mid-implant is placed constant at $12-\mathrm{mm}$ height from the archwire. The models were broadly divided into two groups.

Group I: Bilateral implants placed at different heights (7, 10, and $13 \mathrm{~mm})$ in between the second premolar and first molar (Fig. 1).

Group II: Along with bilateral implants (7, 10, and $13 \mathrm{~mm}$ ), an additional mid-implant is placed in between the two central incisors at 12-mm height from the archwire (Fig. 2).

Comparing the consolidation and non-consolidation, the consolidated arches in group I showed more palatal tipping whereas non-consolidated models showed labial flaring of the teeth as crown moves labially and apex moves palatally, which is unfavorable. Whereas in group II, bodily movements are observed in consolidation and in non-consolidation system, the labial flaring of centrals and laterals are observed. The center of resistance for the present study model might be located at $10-\mathrm{mm}$ height as the bodily movement is seen in 10-mm implant and 9-mm anterior retraction hook with consolidation in

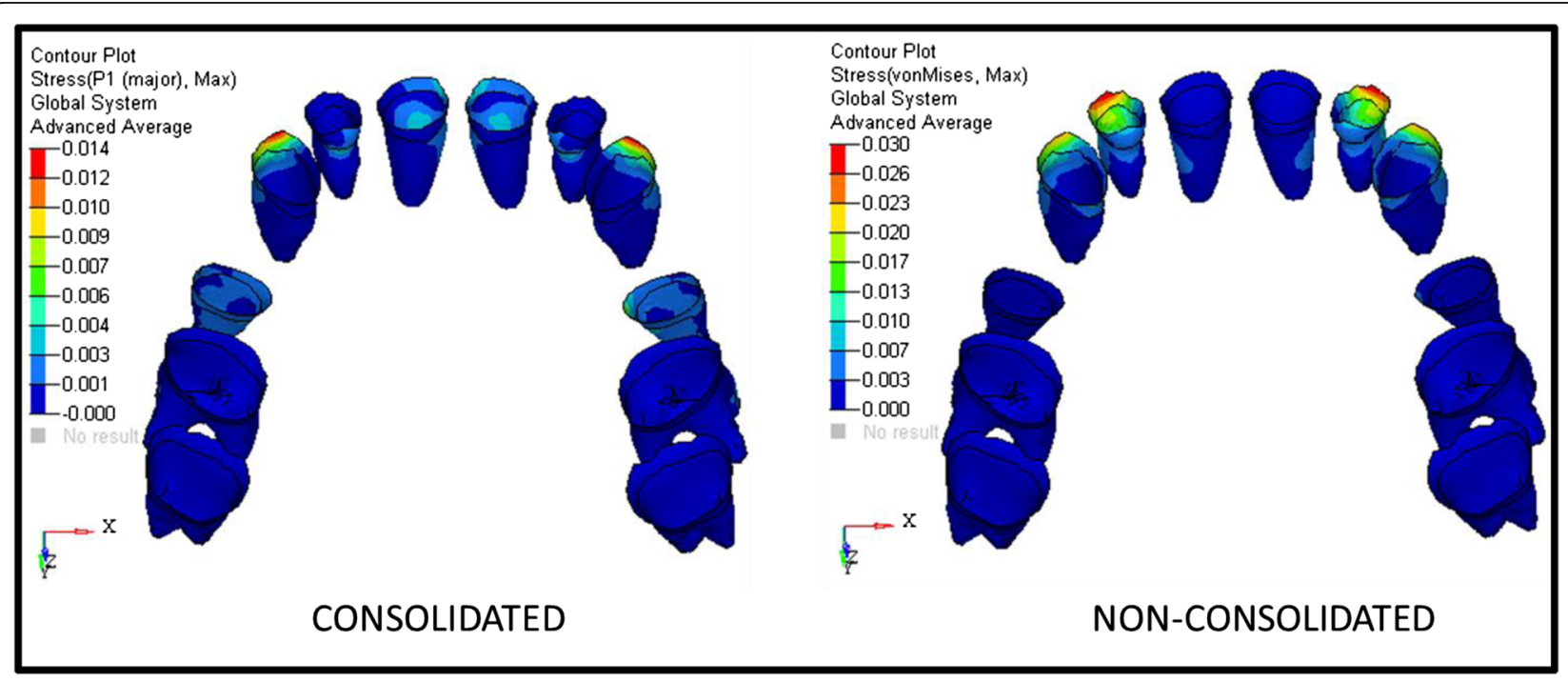

Fig 6 Stress distribution patterns in PDL 
Table 5 Stresses on PDL in Mega Pascal in group I and group II in consolidation models

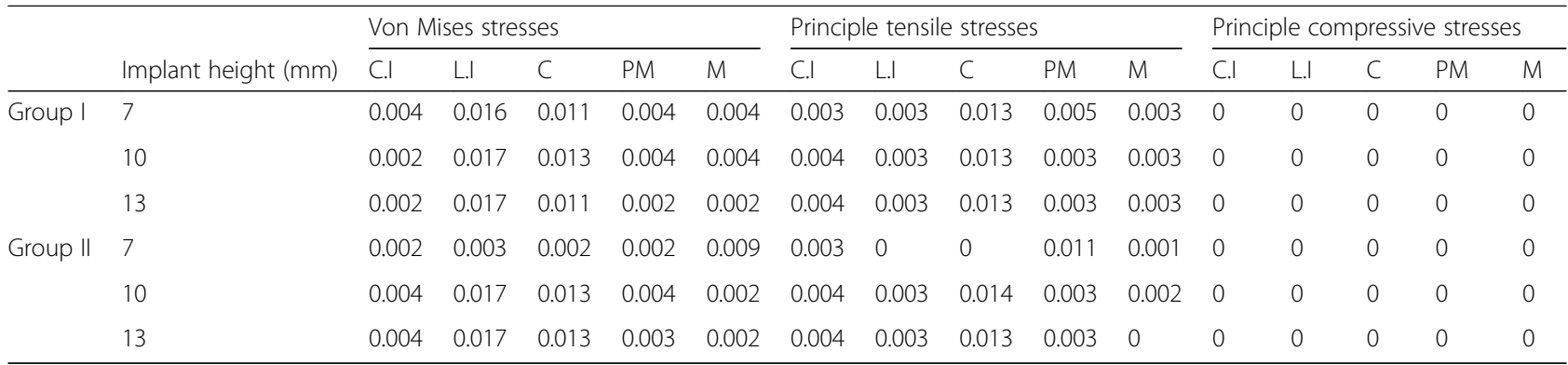

Inference: $C . I$ central incisor, L.I lateral incisor, $C$ canine, $P M$ premolar, $M$ molar

Group I: Highest von Mises stress are observed in laterals (0.017) at 10- and 13-mm implant height followed by canines at 10-mm implant height (0.013) and centrals at $7-\mathrm{mm}$ implant height $(0.004)$. Principle tensile stresses are more in canines in all models $(0.013)$ and no compressive stresses registered

Group II: Principle tensile stresses are high in premolars in 7-mm implant height model (0.011) and von Mises stresses are more in 10- and 13-mm implant height models in laterals (0.017) and canines (0.013). Principle tensile stresses are more in canines in 10- and 13-mm implant height models $(0.014$ and 0.013 , respectively), and no compressive stresses are observed

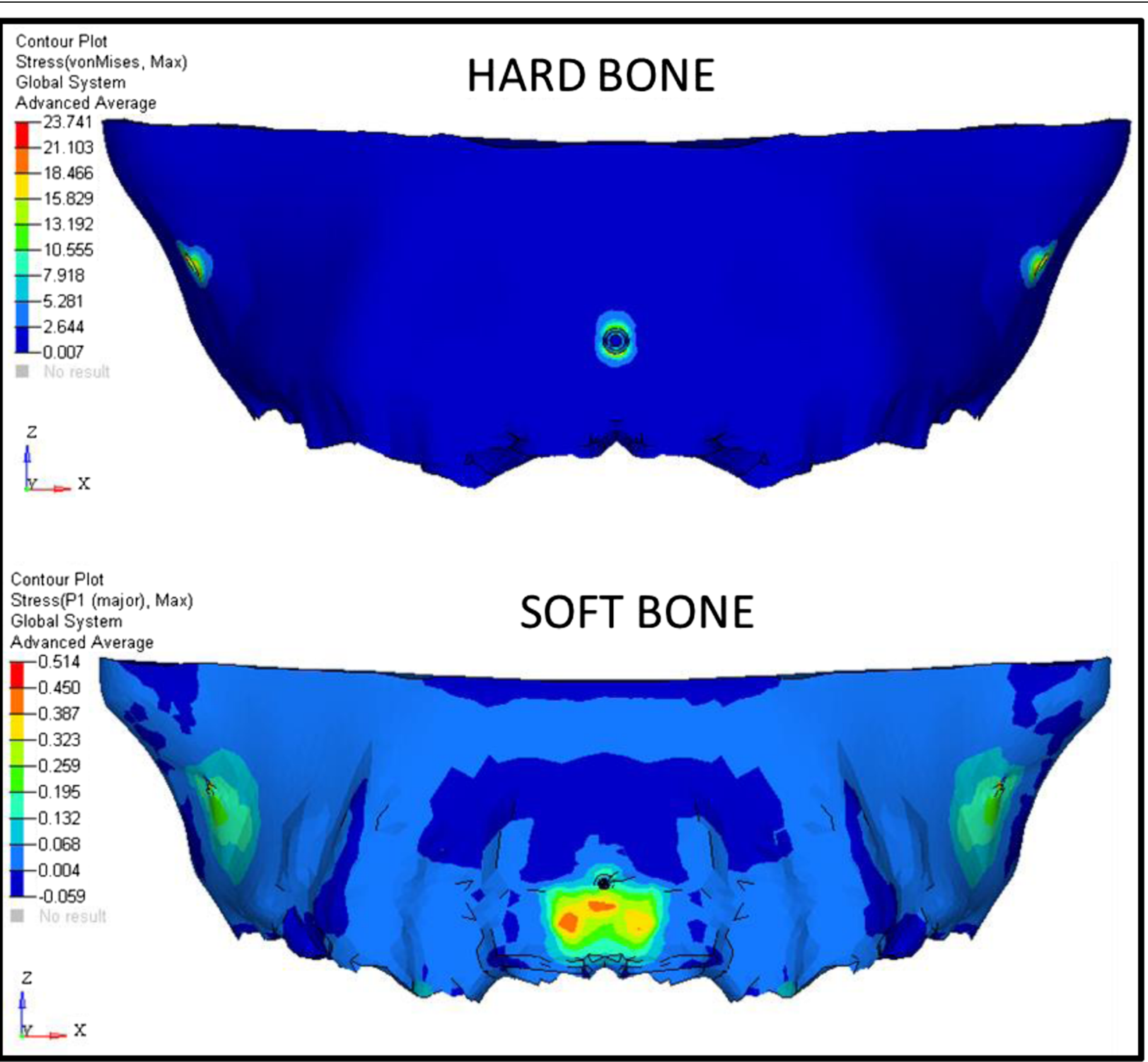

Fig. 7 Stress distribution patterns in the hard bone and soft bone 
Table 6 Stresses on PDL in group I and group || non-consolidated models (MPa)

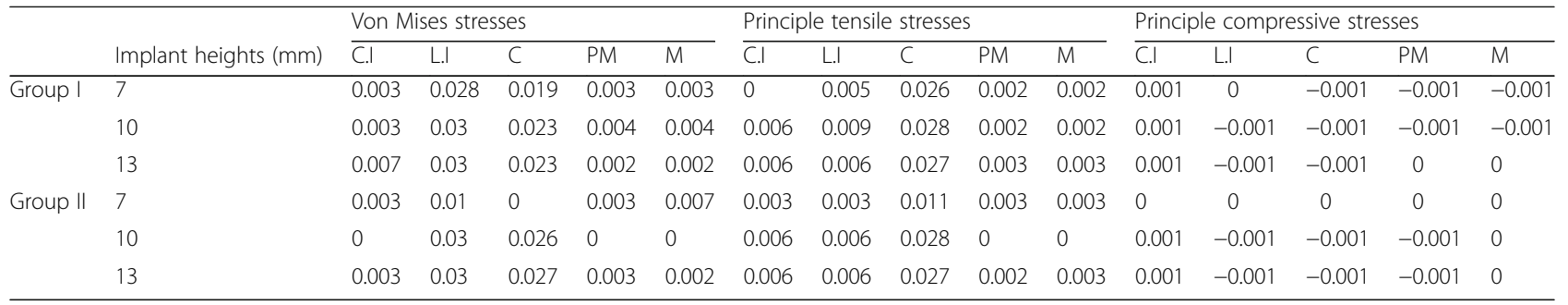

Inference: +ve: tensile stresses; -ve: compressive stresses

Group I: Von Mises stresses are more in laterals in 10- and 13-mm implant heights (0.030) in canines at 10- and 13-mm implant heights (0.023) and centrals in 13-mm implant height (0.007). Principle tensile stresses are more in 10- $\mathrm{mm}$ canines (0.028) and laterals (0.009) and centrals (0.006) at 10- and $13-\mathrm{mm}$ implant heights. Compressive stresses are present in all teeth except in 7- $\mathrm{mm}$ implant height in lateral, 13-mm implant height in premolars and molars

Group II: Von Mises stresses are more in canines in 10- and 13- $\mathrm{mm}$ implant heights ( 0.026 and 0.027 , respectively). Principle tensile stresses are more in canines in 10 - and $13-\mathrm{mm}$ implant height ( 0.028 and 0.027 , respectively). Compressive stresses are not observed in 7 -mm implant height, and stresses are not observed in molars at 10- and 13-mm implant heights

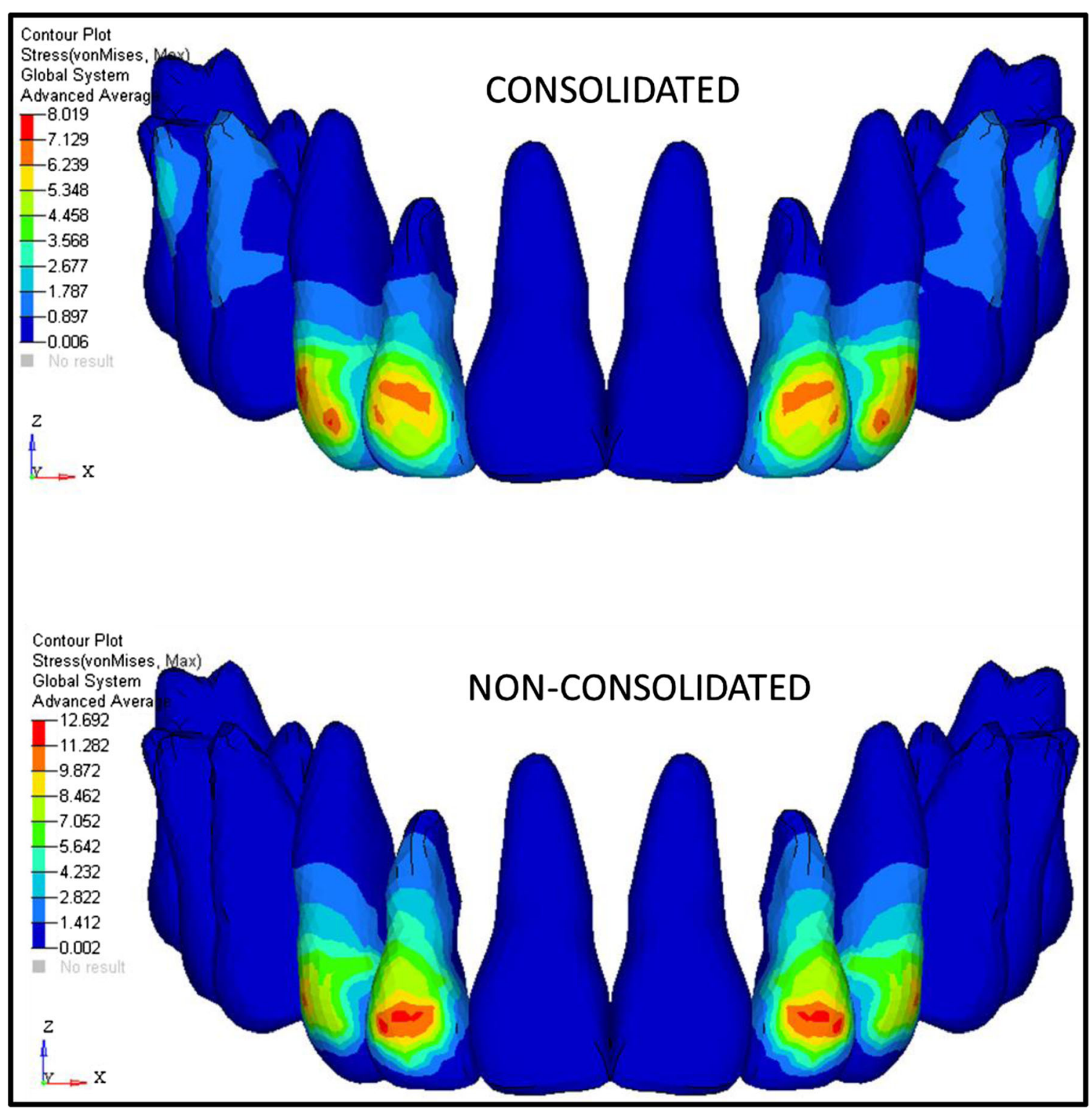

Fig. 8 Stress distribution patterns on the teeth 
Table 7 Stresses on the hard bone and soft bone around the implant area in consolidated and non-consolidated in group I and group II models (Mpa)

\begin{tabular}{|c|c|c|c|c|c|c|c|c|c|}
\hline & & \multicolumn{2}{|c|}{ Max von Mises stress in consolidation } & \multicolumn{2}{|c|}{$\begin{array}{l}\text { Max von Mises stress in } \\
\text { non-consolidation }\end{array}$} & \multicolumn{2}{|c|}{ Max principal stress in consolidation } & \multicolumn{2}{|c|}{$\begin{array}{l}\text { Max principal stress in } \\
\text { non-consolidation }\end{array}$} \\
\hline & & Hard & Soft & Hard & Soft & Hard & Soft & Hard & Soft \\
\hline \multirow[t]{3}{*}{ Group I } & $7 \mathrm{~mm}$ & 29.04 & 0.99 & 29.1 & 0.99 & 32.85 & 1.15 & 32.9 & 1.15 \\
\hline & $10 \mathrm{~mm}$ & 25.9 & 0.6 & 26 & 0.6 & 29.3 & 0.72 & 29.3 & 0.72 \\
\hline & $13 \mathrm{~mm}$ & 22.35 & 0.5 & 22.42 & 0.5 & 26.17 & 0.56 & 26.26 & 0.56 \\
\hline \multirow[t]{3}{*}{ Group ॥ } & $7 \mathrm{~mm}$ & 35.9 & 1.24 & 35.9 & 1.24 & 40.9 & 1.39 & 41 & 1.39 \\
\hline & $10 \mathrm{~mm}$ & 25.67 & 0.6 & 25.75 & 0.6 & 29.35 & 0.7 & 29.45 & 0.7 \\
\hline & $13 \mathrm{~mm}$ & 23.74 & 0.049 & 23.59 & 0.5 & 31.04 & 0.51 & 30.85 & 0.51 \\
\hline
\end{tabular}

Group I: Von Mises stresses and principle stresses are more in both consolidations and non-consolidation in the hard and soft bone at 7-mm implant height Group II: Von Mises stresses and principle stresses are more in both consolidations and non-consolidation in the hard and soft bone at 7-mm implant height

group II. The force levels passing away from the center of resistance will cause tipping and at the center of resistance causes bodily movement which is proved correct in the present study. Abhishek Parashar et al. [38] conducted a study and inferred that the bodily movement with very minimal torque loss was observed with $8-\mathrm{mm}$ implant and concluded the same.

In vertical displacements, it is concluded that intrusion is seen in three implant system as expected. Intrusive movement was more in the high pull implant than in the low pull and medium pull implant in all cases. The force levels passing from the high pull implant to the retraction hook will cause intrusion and from the medium pull implants shows bodily movement and low pull implant showed tipping forces. A study conducted by Shrinivas S Ashekar et al. [39] suggest that the force levels passing from the high pull implant to the retraction hook will cause intrusion and from the medium pull implant shows bodily movement and the low pull implant showed tipping forces which supports the present study. So, the high pull implants show high intrusive effect, and the canines showed extrusion in all cases as the retraction force is more towards the canine as the tipping of the canines is observed. In consolidation and non-consolidation systems, the intrusion effect is high in non-consolidated system than in the consolidated system as the force are distributed among the teeth in consolidated arches, so less intrusive effect is seen in consolidation.

The present study showed highest stresses on lateral incisors, and this may be due to the short roots of the

Table 8 Results

\begin{tabular}{lll}
\hline & Consolidated & Non-consolidated \\
\hline Anterio-posterior & Palatal tipping & Labial flaring \\
Vertical & Less intrusive force & More intrusive force \\
Stress on PDL & Less stress & More stress \\
Stress on the hard bone & Less stress & More stress \\
Stress on the teeth & Less stress & More stress \\
\hline
\end{tabular}

lateral incisors [40]. Burstone and Viecilli [41] stated that it is a natural concept that larger teeth have more PDL and root support than smaller teeth, and hence, when the same load is applied, the stress magnitudes in the PDL for larger teeth are smaller and larger for smaller teeth. Consequently, the resistance to tooth movement of larger teeth is larger compared to smaller teeth. The maxillary molars suggested that widely divergent roots will require higher loads (causing rotation about the vertical axis of the root) to achieve similar levels of stress, even if the surface area of the root is similar to other less divergent tooth roots and this supports the present study [42].

Stresses on PDL are high in laterals and canines compared to other teeth in all cases, and in $7 \mathrm{~mm}$ with mid-implant model (group II), the stresses are more in the posterior teeth than in the anterior teeth and consolidated system showed less stresses when compared with the non-consolidated system. Unfavorable compressive stresses are seen in non-consolidated group, which concluded that consolidation is better than nonconsolidation as the stresses are distributed in consolidation system.

Stresses on the hard bone at the implant area in consolidation and non-consolidation in group I and group II inferred that the stresses on the implant area are more in non-consolidated models than in consolidated models in all groups, and the von Mises stresses are equal in group II 7-mm implant model. Stresses on the soft bone around the implant area in consolidation and non-consolidation at different implant heights are equal in all models. In $13-\mathrm{mm}$ three implant model (group II), von Mises stresses are more in nonconsolidated model than in consolidated models. Seven-millimeter implants showed highest stresses in the hard and soft bone in all cases. This concludes that low pull implants with high anterior hook produces more stresses in the bone around the implant area (Table 9). 
Table 9 Stresses in the implant in group I and group II consolidated and non-consolidated models

\begin{tabular}{|c|c|c|c|c|c|}
\hline & & $\begin{array}{l}\text { Max von Mises stress } \\
\text { in consolidation }\end{array}$ & $\begin{array}{l}\text { Max von Mises stress } \\
\text { in non-consolidation }\end{array}$ & $\begin{array}{l}\text { Max principal stress } \\
\text { in consolidation }\end{array}$ & $\begin{array}{l}\text { Max principal stress } \\
\text { in non-consolidation }\end{array}$ \\
\hline \multirow[t]{3}{*}{ Group I } & $7 \mathrm{~mm}$ & 108.4 & 108.7 & 116 & 116.2 \\
\hline & $10 \mathrm{~mm}$ & 106.6 & 106.9 & 116.2 & 116.5 \\
\hline & $13 \mathrm{~mm}$ & 106.1 & 106.4 & 109.5 & 109.8 \\
\hline \multirow{3}{*}{$\begin{array}{l}\text { Group } \\
\text { ॥ }\end{array}$} & $7 \mathrm{~mm}$ & 135.1 & 135.1 & 144.5 & 144.5 \\
\hline & $10 \mathrm{~mm}$ & 106.6 & 106.9 & 116.2 & 116.6 \\
\hline & $13 \mathrm{~mm}$ & 106.1 & 106.4 & 109.5 & 109.8 \\
\hline
\end{tabular}

Group I: Von Mises stresses are high in 7-mm implant height, and principle stresses are more in 10-mm implant height in consolidation and non-consolidation Group II: Von Mises stresses and principle stresses are high in 7-mm implant height in consolidation and non-consolidation

Stresses on the teeth showed more stresses on laterals. This is supported by the study conducted by S. Reimann [30] as the study showed the similar results. But in group II, 7-mm implant height model showed highest stresses on the posterior teeth. In consolidation and non-consolidation in group I and group II, it is inferred that the stresses are more in the non-consolidated models than in the consolidated models in all cases. This suggests that consolidation is important in the case of en-masse retraction with anterior retraction hook (Table 10).

So, the present study concludes that consolidation is better than non-consolidation in retraction using implant with anterior retraction hook, and intrusion is effective in three implants than bilateral implants.

\section{Conclusions}

The following important conclusions are drawn from this study:

1. Bodily movement was observed when implant was placed at 10-mm height in both group I and group II, this seems to be the ideal height for bilateral implant position for retraction of the anterior teeth.
2. In three implant system, more intrusion is seen than two implant system. The three implant system is better for intrusion of the anterior teeth.

3. The stresses in PDL are more in the two implant system than in the three implant system in all the anterior teeth.

4. Undesirable labial flaring of teeth are observed in nonconsolidation in two implant and three implant system.

5. The stresses on the hard bone, PDL, and implant showed less stresses in consolidation and more in non-consolidation.

6. Intrusion and retraction is better in consolidated arches and also less stresses were observed on the teeth, PDL, bone, and implant.

7. Force levels passing from the high pull implant to the retraction hook will cause intrusion and from the medium pull implant shows bodily movement and low pull implant showed tipping forces in consolidated arches.

This study suggests that with consolidation of the anterior teeth, desirable tooth movement can be achieved with less stresses on all surrounding structures.

Table 10 Stresses on teeth (laterals) in group I and group II consolidated and non-consolidated models

\begin{tabular}{|c|c|c|c|c|c|}
\hline & & $\begin{array}{l}\text { Max von Mises stress } \\
\text { in consolidation }\end{array}$ & $\begin{array}{l}\text { Max von Mises stress in } \\
\text { non-consolidation }\end{array}$ & $\begin{array}{l}\text { Max principal stress } \\
\text { in consolidation }\end{array}$ & $\begin{array}{l}\text { Max principal stress in } \\
\text { non-consolidation }\end{array}$ \\
\hline \multirow[t]{3}{*}{ Group I } & $7 \mathrm{~mm}$ & 8.02 & 11.26 & 6.04 & 9.45 \\
\hline & 10 mm & 8.4 & 12.4 & 6.4 & 10.5 \\
\hline & 13 mm & 8.11 & 12.6 & 6.17 & 10.73 \\
\hline \multirow[t]{3}{*}{ Group II } & $7 \mathrm{~mm}$ & 3.24 & 4.92 & 2.92 & 3.98 \\
\hline & 10 mm & 8 & 12.85 & 6.23 & 10.93 \\
\hline & 13 mm & 8.15 & 13.1 & 5.9 & 11.15 \\
\hline
\end{tabular}

\footnotetext{
Inference: (laterals recorded the highest stresses in all models)
}

Group I: In consolidation, 10-mm implant height and non-consolidation 13-mm implant height showed highest von Mises stresses. Principle tensile stresses are high in 10-mm consolidation implant model and 13-mm non consolidation implant model 


\section{Authors' contributions}

MN is the principle investigator of the study and oversaw the progress of the study. NSR: helped in framing the study design and headed the project work. SCK: helped in writing the manuscript and coordinated the project work. NC: helped in framing the project and collection of articles. CHR: participated in the writing. KSK: Helped in analysis and write up.

\section{Competing interests}

The authors declare that they have no competing interests.

\section{Ethics approval and consent to participate}

Not applicable.

Received: 11 February 2016 Accepted: 14 November 2016 Published online: 09 January 2017

\section{References}

1. Chetan S, Keluskar KM, Vasisht VN, Revankar S. En-masse retraction of the maxillary anterior teeth by applying force from four different levels-a finite element study. J Clin Diagn Res. 2014;8(9):ZC26-30.

2. Park H-S, Kwon T-G. Sliding mechanics with microscrew implant anchorage. Angle Orthod. 2004;74:703-10.

3. Kojima Y, Kawamura J, Fukui H. Finite element analysis of the effect of force directions on tooth movement in extraction space closure with miniscrew sliding mechanics. Am J Orthod Dentofacial Orthop. 2012;142:501-8.

4. Ren Y, Maltha JC, van't Hof MA, Kuijpers-Jagtman AM. Optimum force magnitude for orthodontic tooth movement: a Mathematic model. Am J Orthod. 2004;125(1).

5. Salehi P, Torkan S, Roeinpeikar SMM. Orthodontics — basic aspects and clinical considerations: the use of mini-implants (temporary anchorage devices) in resolving orthodontic problems: www.intechopen.com as sited on October $10^{\text {th }}$ 2015. http://www.intechopen.com/books/ orthodontics-basic-aspects-and-clinical-considerations/the-use-of-miniimplants-temporaryl-anchorage-devices-in-resolving-orthodontic-problemsa-case-serie.

6. Marassi C, Marassi C. Mini-implant assisted anterior retraction. Dental Press J Orthod. 2008:13(5):57-74

7. Knop L, Gandini Jr LG, Shintcovsk RL, Gandini MR. Scientific use of the finite element method in orthodontics. Dental Press J Orthod. 2015 20(2):119-25.

8. Rex S. Balasubhramanyam, Evaluation of apical force distribution for orthodontic tooth movement. J Indian Orthod Soc. 2010:58-62.

9. Panna, Rajesh Podar, Anjali Miglani, Anil Dhingra. Finite element analysis_an insight. Indian J Dental Sci. 2014;6(1)E ISSN NO. 2231-2293 P ISSN NO. 0976-4003.

10. Singh S, Mogra S, Shetty VS, Shetty S, Philip P. Three-dimensional finite element analysis of strength, stability, and stress distribution in orthodontic anchorage: a conical, self-drilling miniscrew implants system. Am J Orthod Dentofacial Orthop. 2012;141:327-36.

11. Kumar Marimuthu V, Kumar K, Sadhasivam N, Arasappan R, Jayamurugan A, Rathinasamy R. Finite element analysis of stress and displacement around mini-implant using different insertion angles and various direction of orthodontic force in maxilla and mandible. J Indian Orthod Soc. 2015;2:61-6.

12. Andersen $\mathrm{KL}$, Pedersen $\mathrm{EH}$, Melsen B. Material parameters and stress profiles within the periodontal ligament. Am J Orthod Dentofacial Orthop. 1991:99:427-40

13. Rudolph DJ, Willes MG, Sameshima GT. A finite element model of apical force distribution from orthodontic tooth movement. Angle Orthod. 2001;71:127-31

14. Toms SR, Lemons JE, Bartolucci AA, Eberhardt AW. Nonlinear stress-strain behaviour of periodontal ligament under orthodontic loading. Am J Orthod Dentofacial Orthop. 2002;122:174-9.

15. Toms SR, Eberhardt AW. A nonlinear finite element analysis of the periodontal ligament under orthodontic tooth loading. Am J Orthod Dentofacial Orthop. 2003:123:657-65.

16. Viecilli RF, Katona TR. Three-dimensional mechanical environment of orthodontic tooth movement and root resorption. Am J Orthod Dentofacial Orthop. 2008;133:791e11-26.
17. Xia Z. Estimation of periodontal ligament's equivalent mechanical parameters for finite element modeling. Am J Orthod Dentofacial Orthop. 2013;143:486-91.

18. Su J, Liu J, Zhang D. Finite-element investigation on center of resistance of maxillary anterior teeth. Sheng Wu Yi Xue Gong Cheng Xue Za Zhi. 2014;31(5):994-1000.

19. Carano A, Velo S, Leone P, Siciliani G. Clinical applications of the miniscrew anchorage system. J Clin Orthod. 2005;39(1):9-24.

20. Sung S-J, Jang G-W, Chun Y-S, Moon Y-S. Effective en-masse retraction design with orthodontic mini-implant anchorage: a finite element analysis. Am J Orthod Dentofacial Orthop. 2010;137:648-57.

21. Su J, Liu J, Xu L, Zhong P, Zhang D. Three-dimensional finite element analysis on En mass intrusion and retraction of maxillary anterior teeth with J-hook headgear. Zhonghua Kou Qiang Yi Xue Za Zhi. 2015;50(2):84-8.

22. Perillo $L$, Jamilian $A$. Finite element analysis of miniscrew placement in mandibular alveolar bone with varied angulations. Eur J Orthod. 2015;56-59. doi:10.1093/ejo/cju006.

23. Padmawar SS, Belludi A, Makhija PG, Bharadwaj A, Virang B. Stress appraisal with simulation of en masse absolute intrusion of maxillary anteriors deploying strategic mini-implant locations: a finite element analysis. J Indian Orthod Soc. 2012;46(2):77-81.

24. Zhang DQ, Su JH, Xu LY, Zhong PP. 3D finite element study of en masse retraction of maxillary anterior teeth in two typical force directions. Chin J Dental Res. 2008;11:101-7.

25. Kim T, Suh J. Optimum conditions for parallel translation of maxillary anterior teeth under retraction force determined with the finite element method. Am J Orthod Dentofacial Orthop. 2010;137:639-47.

26. Shyagali TR, Bhayya DP, Chandralekha B, Subramaniam S. Finite element study on modification of bracket base and its effects on bond strength. Dental Press J Orthod. 2015:20(2):76-82.

27. Papageorgiou SN, Keilig L, Hasan I, Jäger A, Bourauel C. Effect of material variation on the biomechanical behaviour of orthodontic fixed appliances: a finite element analysis. Eur J Orthod. 2016;38(3):300-7.

28. Upadhyay M, Yadav S, Patil S. Mini-implant anchorage for en-masse retraction of maxillary anterior teeth: a clinical cephalometric study. Am J Orthod Dentofacial Orthop. 2008:134:803-10.

29. Qamaruddin I, Nazir M, Khalid MT, Alam M, Shahid F. Factors that contribute to the failure of orthodontic mini-implants: a literature review. Pak Orthod J. 2010;2(2):76-81.

30. lijima M, Takano M, Yasuda Y, Muguruma T, Nakagaki S, Sakakura Y, Ochi M. Effect of the quantity and quality of cortical bone on the failure force of a miniscrew implant. Eur J Orthod. 2013;35(5):583-9.

31. Tominaga JY, Tanaka M, Koga Y, Gonzales C, Kobayashi M, Yoshida N. Optimal loading conditions for controlled movement of anterior teeth in sliding mechanics. A 3D finite element study. Angle Orthod. 2009;79(6):1102-7.

32. Shaw AM, Sameshima GT, Vu HV. Mechanical stress generated by orthodontic forces on apical root cementum: a finite element model. Orthod Craniofac Res. 2004;7:98-107.

33. German A, Sodagar A, Hassanpour M. Three-dimensional analysis using finite element method of anterior teeth inclination and center of resistance location. Chin J Dental Res. 2014;1:37-42.

34. Hemanth M, Deoli S. Stress induced in periodontal ligament under orthodontic loading (Part II): a comparison of linear versus non-linear FEM study. J Int Oral Health. 2015;7(9):114-8.

35. Lim JE, Lim WH, Chun YS. Cortical bone thickness and root proximity at mandibular interradicular sites: implications for orthodontic mini-implant placement. koreamed.org October 06, 2008.

36. Issa Fathima Jasmine M, Arif Yezdani A, Faisal T, Murali Venu R. Analysis of stress in bone and micro implants during en-masse retraction of maxillary and mandibular anterior teeth with different insertion angulations: a 3-dimensional finite element analysis study. Am J Orthod Dentofacial Orthop. 2012;141:71-80.

37. Chugh T, et al. Quantitative assessment of interradicular bone density in the maxilla and mandible: implications in clinical orthodontics. Prog Orthod. 2013:14:38

38. Parashar A, Aileni KR, Rachala MR. Torque loss in en-masse retraction of maxillary anterior teeth using miniimplants with force vectors at different levels: 3D FEM study. J Clin Diagn Res. 2014;8(12):ZC77-80.

39. Ashekar SS, Deshpande RS, Shetty P, Patil SS. Evaluation of optimal implant position and height of retraction hook for intrusive and bodily movement of anterior teeth in sliding mechanics: a FEM study. J Indian Orthod Soc 2013;47(4):479-82. 
40. Bohm Choi, Dong-Ok Lee, Sung-Seo Mo, Seong-Hun Kim. Threedimensional finite element analysis for determining the stress distribution after loading the bone surface with two-component mini-implants of varying length. Korean J Orthod. 2011;41(6):423-430.

41. Viecilli RF, Burstone CJ. Ideal orthodontic alignment load relationships based on periodontal ligament stress. Orthod Craniofac Res. 2015;18:180-6.

42. Geramy A. Apical third morphology and intrusive force application: 3D finite element analysis. Journal of Dentistry, Tehran University of Medical Sciences, Tehran, Iran. 2007;4(3)130-134.

\section{Submit your manuscript to a SpringerOpen ${ }^{\circ}$ journal and benefit from:}

- Convenient online submission

- Rigorous peer review

- Immediate publication on acceptance

- Open access: articles freely available online

- High visibility within the field

- Retaining the copyright to your article

Submit your next manuscript at $>$ springeropen.com 